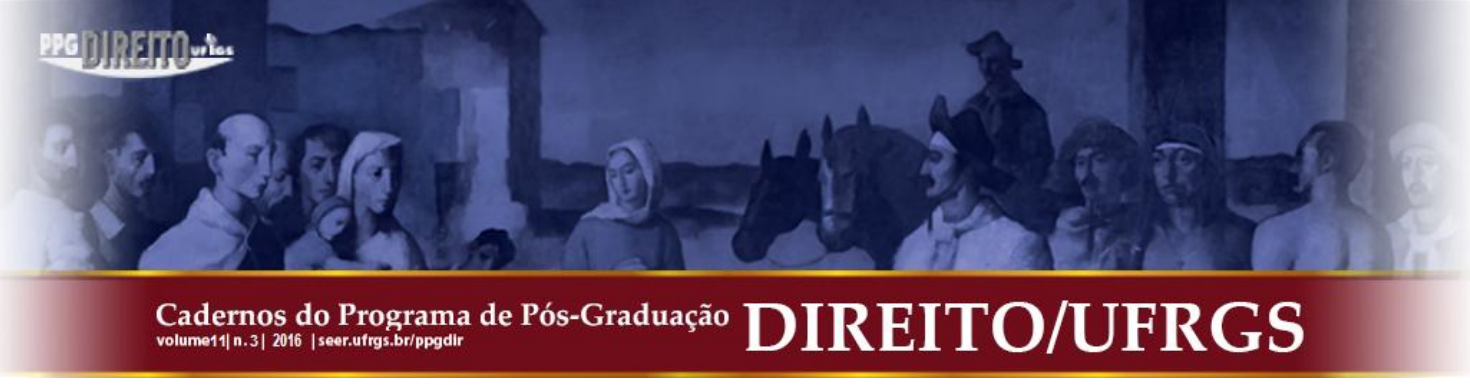

\title{
FUNDAMENTOS DOS CONCEITOS DE HERMENÊUTICA JURÍDICA E DE INTERPRETAÇÃO EM CARLOS MAXIMILIANO
}

\author{
FUNDAMENTALS OF THE CONCEPTS OF LEGAL HERMENEUTICS AND \\ INTERPRETATION IN CARLOS MAXIMILIANO
}

Pablo Castro Miozzo*

\begin{abstract}
RESUMO: O presente trabalho se ocupa do pensamento de Carlos Maximiliano acerca da hermenêutica jurídica e da interpretação, procurando investigar as bases a partir das quais ele se alicerça. Num primeiro momento, será investigada a obra de Francisco de Paula Baptista, com a qual Maximiliano dialoga criticamente, procurandose estabelecer as pressupostos teórico-filosóficos do conceito de interpretação daquele autor. Num segundo momento, serão apresentadas concepções de Maximiliano em si, bem como as teorias que parecem estar na base de seu pensamento e que sustentam a sua crítica ao conceito de interpretação de Paula Baptista, em especial a hermenêutica de Schleiermacher e a metodologia jurídica de Savigny.
\end{abstract}

PALAVRAS-CHAVE: Hermenêutica Jurídica. Interpretação do Direito. "In claris non fit interpretatio".
ABSTRACT: This work paper lay emphasis on the thinking of Carlos Maximiliano about legal hermeneutics and interpretation, seeking to investigate the bases from which it is founded. At first, it will investigate the work of Francisco de Paula Baptista, with whom Maximiliano critically dialogues, seeking to establish the theoretical and philosophical assumptions of the concept of interpretation of the former author. Secondly, the very conception of Maximiliano will be presented, as well as the theories that seem to be on the basis of his thinking, and at the same time supports its criticism against the concept of interpretation of Paula Baptista, especially the hermeneutics from Schleiermacher and the legal methodology from Savigny.

KEYWORDS: Legal Hermeneutics. Interpretation of Law. "In claris non fit interpretatio".

SUMÁRIO: Introdução1 Os Conceitos de Hermenêutica Jurídica e de Interpretação em Francisco de Paula Baptista. 2 Os Conceitos de Hermenêutica Jurídica e de Interpretação em Carlos Maximiliano. 3 O Conceito de Interpretação na Hermenêutica Geral de Schlei ermacher e na Metodologia Absoluta de Savigny. 3.1 Friedrich Daniel Ernst Schleiermacher. 3.2 Friedrich Carl von Savigny. 4 O Papel do Intérprete e o Conceito de Aplicação do Direito em Carlos Maximiliano. Considerações Finais. Referências.

\section{INTRODUÇÃO}

Carlos Maximiliano (1873-1960) possui uma obra clássica no Brasil sobre hermenêutica jurídica, intitulada "Hermenêutica e Aplicação do Direito". Trata-se de texto publicado em 1924, que expressa extrema erudição e atualidade em termos do debate que se desenvolvia então, tanto no Brasil quanto na Europa, em especial na Alemanha, França, Suíça e Inglaterra, bem como ainda na tradição americana.

O que se pretende com a presente investigação é realizar uma reconstrução dos fundamentos dos conceitos de hermenêutica e de interpretação que estão na base do pensamento do autor. Maximiliano dialoga de forma crítica com a obra do jurista brasileiro Francisco de Paula Baptista (1811-1882). Os modelos de hermenêutica e de interpretação

\footnotetext{
* Doutorando em Direito pela Universidade de Freiburg (Albert-Ludwigs-Universität Freiburg), Alemanha. Mestre pelo Programa de Pós-Graduação em Direito da Universidade Federal do Rio Grande do Sul (UFRGS). 


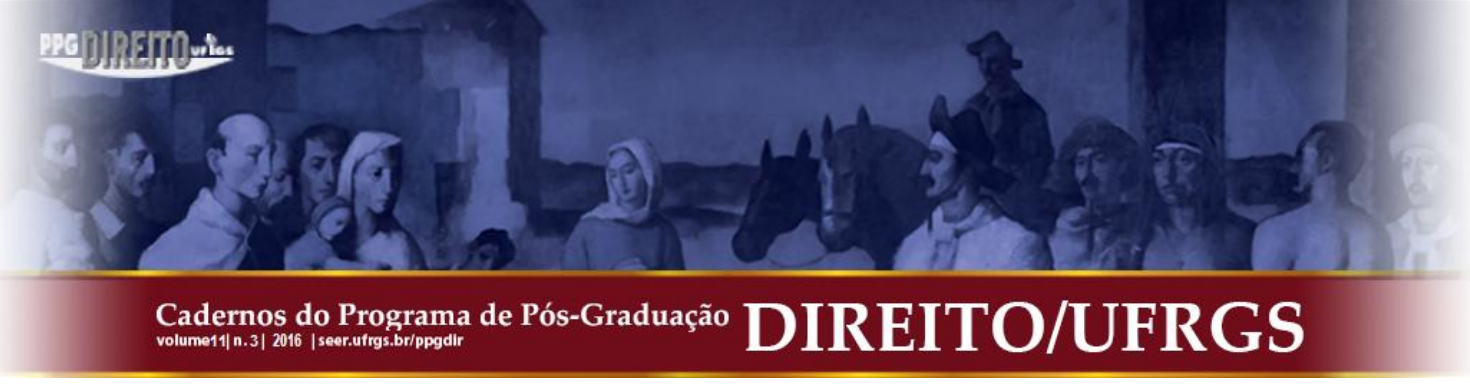

presentes em Francisco de Paula Baptista e Carlos Maximiliano se assemelham em vários aspectos no que tange às suas especificidades, divergem frontalmente, no entanto, em seu fundamento central, sendo lícito dizer que são corolários de dois paradigmas ${ }^{1}$ filosóficos e hermenêutico-jurídicos distintos.

É possível afirmar que o modelo hermenêutico de Paula Baptista foi influenciado pela assim designada "hermenêutica iluminista", enquanto que Maximiliano adota alguns dos fundamentos da "hermenêutica romântica", cujos principais representantes são Schleiermacher (1768-1834), no âmbito da filosofia, e Savigny (1779-1861), no âmbito do Direito. Parte-se aqui do pressuposto de que compreender este choque de paradigmas que está por trás dos modelos de Paula Baptista e Carlos Maximiliano pode lançar luzes para uma compreensão adequada da proposta deste último.

A metodologia empregada será basicamente a revisão bibliográfica, com foco na análise do discurso de Maximiliano em sua obra principal, dando-se destaque para os momentos em que ele articula os conceitos de hermenêutica e de interpretação, que são chave para o presente trabalho.

\section{OS CONCEITOS DE HERMENÊUTICA JURÍDICA E DE INTERPRETAÇÃO EM FRANCISCO DE PAULA BAPTISTA ${ }^{2}$}

Francisco de Paula Baptista publicou, pela primeira vez, na década de sessenta do século XIX, um compêndio de hermenêutica jurídica que fora adotado como livro oficial para o ensino desta disciplina nas faculdades de Direito do então Império do Brasil (COSTA, 1984. p. 86). Trata-se de uma obra concisa, porém profunda, escrita na forma de aforismos. Interessa aqui, sobretudo, não dar conta de seu conteúdo na íntegra, mas tão somente sondar os conceitos de hermenêutica e de interpretação do Direito nela presentes, a fim de

\footnotetext{
${ }^{1} \mathrm{O}$ termo aqui é tomado a partir do pensamento de Thomas Kuhn como "[...] realizações científicas universalmente reconhecidas que, durante algum tempo, fornecem problemas e soluções modelares para uma comunidade de praticantes de uma ciência" (KUHN, 1970, p. IV, tradução livre). Segundo o autor, “[...] Homens cuja pesquisa está baseada em paradigmas compartilhados estão comprometidos com as mesmas regras e padrões para a prática científica. Esse compromisso e o aparente consenso que produz são pré-requisitos para a ciência normal, isto é, para a gênese e a continuação de uma determinada tradição de pesquisa" (KUHN, 1970, p. 11, tradução livre).

${ }^{2}$ Francisco de Paula Baptista foi um jurista, político e professor brasileiro. Foi Deputado Geral entre 1850 e 1853 . Tornou-se professor da Faculdade de Direito de Recife em 1835, tendo lecionado por 46 anos. Foi um dos mais importantes juristas do século XIX no país, destacando-se, entre outras, na área do Direito Processual, na qual foi precursor de doutrinas modernas. O seu primiero texto sobre hermêneutica jurídica foi publicada em 1860 como parte do livro "Compêndio de Teoria e Prática do Processo Civil Comparado com o Comercial", de 1855. Trabalha-se aqui com a edição de 1872, revista e ampliada, republicada em 1984. (PAULA BAPTISTA, 1984).
} 


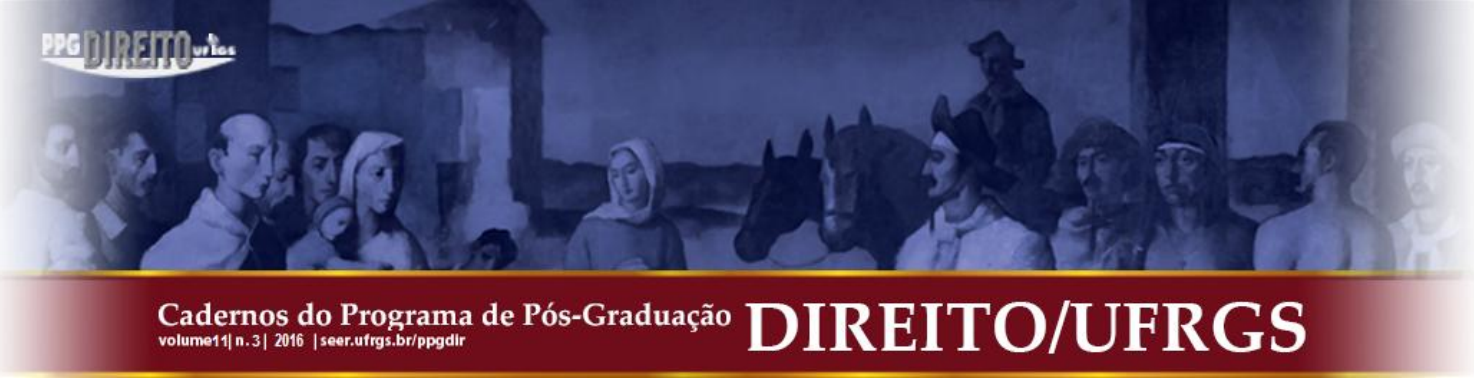

compreender em que medida o pensamento de Carlos Maximiliano com eles dialoga e deles diverge.

Paula Baptista refere no $\S 1^{\circ}$ de seu Compêndio que "Hermenêutica jurídica é o sistema de regras para interpretação das leis”. Em seguida, no $\S 2^{\circ}$, aduz que a importância desta disciplina deriva do interesse público de que "as leis tenham aplicação fiel ao pensamento do legislador”. Já com relação ao conceito de interpretação e a quando ela tem lugar, afirma no $\S 3^{\circ}$ :

Interpretação é a exposição do verdadeiro sentido de uma lei obscura por defeitos de sua redação, ou duvidosos com relação aos fatos ocorrentes ou silenciosa. Por conseguinte, não tem lugar sempre que a lei, em relação aos fatos sujeitos ao seu domínio, é clara e precisa. ${ }^{3}$ (PAULA BAPTISTA, 1984, p. 3-4).

$\mathrm{Na}$ linha do exposto, é possível afirmar que o pensamento de Paula Baptista era corolário da assim designada "hermenêutica iluminista". No âmbito da filosofia, Gadamer faz menção ao fato de que, no iluminismo,

[...] compreender e interpretar não são a mesma coisa [...] fica claro que uma passagem que necessita de interpretação é, por princípio, um caso excepcional, e que, em geral, as passagens podem ser entendidas imediatamente, quando conhecemos o assunto de que tratam, seja porque a passagem nos recorda essa coisa, ou porque apenas pela passagem obtemos acesso ao seu conhecimento (GADAMER, 2004, p. 252).

Para a hermenêutica jurídica iluminista a interpretação só tinha lugar diante de textos obscuros, não claros ou de difícil compreensão. Tal imagem acerca da interpretação corresponde, na visão de Stephan Meder, à antiga regra In claris non fit interpretatio (doutrina do Sens-clair na França ou do Clair meaning ou Plain meaning no direito angloamericano (MEDER, 2004, p. 17 e ss.)).

Um dos pressupostos fundamentais da hermenêutica jurídica iluminista, motivo pelo qual se diz que Paula Baptista pode ser visto como seu representante no Brasil, era o de que o intérprete, como regra, é capaz de compreender aquilo que foi desejado pelo autor do texto e que, as situações em que mal-entendidos ou pontos duvidosos ocorrem, são a exceção

\footnotetext{
${ }^{3}$ Segue o autor referindo acerca dos casos em que a interpretação se faz necessária: §25: “A necessidade de interpretar uma lei pode nascer: $1^{\circ}$ ) de defeitos em sua redação, resultando daí a obscuridade e equívoco em seu sentido; $2^{\circ}$ ) da colisão habitual e inevitável com que são escritas todas as leis, nascendo daí dúvidas não em seu sentido direto, mas em sua conformidade ou não-conformidade com os diversos casos correntes, cumprindo, então, salvar incoerências e contradições virtuais de seu espírito com suas palavras; 3) de seu silêncio" (PAULA BAPTISTA, 1984, p. 28).
} 


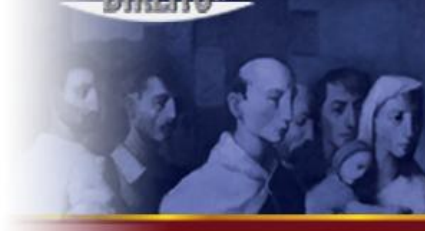

(MEDER, 2004. p. 20). Em outras palavras, a interpretação possui um caráter excepcional e se faz necessária somente diante de mal-entendidos.

\section{OS CONCEITOS DE HERMENÊUTICA JURÍDICA E DE INTERPRETAÇÃO EM CARLOS MAXIMILIANO}

Logo no prefácio à primeira edição da obra "Hermenêutica e Aplicação do Direito", Maximiliano pontua que sua intenção era escrever uma obra baseada na doutrina vigente acerca da interpretação que, na sua opinião, era desconhecida ou intencionalmente ignorada pelos autores brasileiros. Maximiliano dirigiu-se criticamente ao livro de Paula Baptista, sob alegação de que o seu texto se manteve preso ao tradicionalismo (MAXIMILIANO, 1961, p. $65)^{6}$ e que estava atrasado com relação ao debate travado na Europa do século XIX e início do XX, em especial o pensamento de Savigny (1779-1861) e as escolas que lhe sucederam.

Digno de nota é o fato, por óbvio conhecido de Maximiliano, de que algumas das doutrinas por ele citadas, como o Movimento pelo Direito livre ${ }^{7}$, por exemplo, se consolidaram no Velho Continente depois da morte de Paula Baptista. Em razão do exposto, é possível e necessário separar, de um lado, a crítica que Maximiliano faz a Paula Baptista por negar os influxos da Escola Histórica e, de outro, a tentativa que aquele autor faz de apresentar as novas tendências do pensamento hermenêutico até 1924 e seus ulteriores desenvolvimentos nas edições posteriores. O mesmo vale para a eventuais críticas apressadas que possam ser feitas a Maximiliano com base na hermenêutica filosófica de matriz gadameriana, já que quando da publicação de "Verdade e Método" o jusfilósofo brasileiro já havia falecido.

O seguinte trecho da obra de Paula Baptista, que faz expressa menção ao brocardo "In claris", parece dar razão em parte a Maximiliano quanto à filiação teórica daquele autor:

\footnotetext{
${ }^{4}$ Carlos Maximiliano Pereira dos Santos foi Advogado, de 1898 a 1914 e de 1918 a 1934; Deputado Federal, de 1911 a 1914 e 1919 a 1923; Ministro da Justiça e dos Negócios Interiores entre 1914 e 1918; Consultor Geral da República entre 1932 e 1934; Deputado da Assembleia Nacional Constituinte de 1933-1934; Procurador Geral da República, de 1934 a 1936 ; Ministro da Corte Suprema, nomeado em 1936 e aposentado em 1941.

${ }^{5}$ A primeira edição é de 1924. A obra está atualmente na $20^{\mathrm{a}}$ edição, publicada em 2011. Trabalha-se aqui com a $7^{\mathrm{a}}$ edição, primeira edição post mortem, publicada em 1961.

${ }^{6}$ Por "dogmática" tradicional entende Maximiliano a escolástica, ou seja, "[...] sistema primitivo de Hermenêutica, ao que se obstina em jungir o Direito aos textos rígidos e aplicá-lo hoje de acordo com a vontade, verificada ou presumida, de um legislador há muito sepultado" (MAXIMILIANO, 1961. p. 65).

${ }^{7}$ Sobre o Movimento para o Direito livre, seus precursores e seu desenvolvimento, ver (RIEBSCHLÄGER, 1968). 


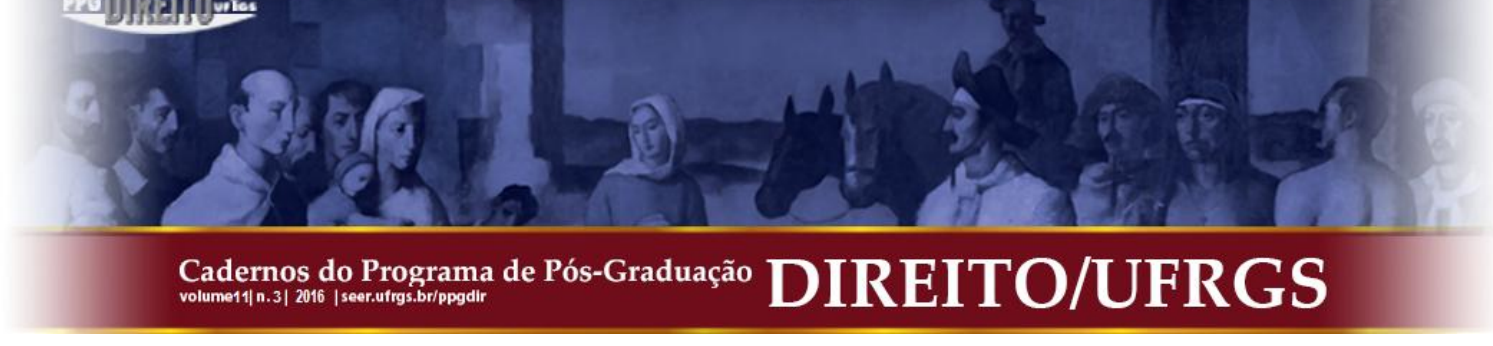

Interpretatio cessat in claris (Cepahl concil 132 n. 2) Quando verba sunt clara, non admittitur mentis interpretatio (L. Continuus, 137, § cum ita, 2, ff., de verb. Oblig.) Savigny (Tratado de direito romano, v.1) censura os que limitam a interpretação aos casos acidentais de obscuridade nas leis; diz que ela acompanha a aplicação de todas as leis à vida real [...] e a define "reconstrução do pensamento contido na lei". Uma semelhante doutrina tão vaga e absoluta, pode fascinar o intérprete, de modo a fazêlo sair dos limites da interpretação para entrar no domínio da formação do direito. $\mathrm{Ou}$ existem motivos para duvidar do sentido de uma lei, ou não existem. No primeiro caso, cabe interpretação, pela qual fixamos o verdadeiro sentido da lei, e a extensão do seu pensamento; no segundo, cabe apenas observar o seu preceito literal. No primeiro caso, há sempre uma questão de direito a decidir; no segundo, porém, poderá haver, quando muito, alguma questão de fato, cuja decisão dependa de apreciação da prova. É verdade que a todo escrito acompanha a condição natural de dever ser entendido segundo o pensamento do seu autor; mas daí se não segue que em todo o escrito se dê a necessidade de tornar esta condição efetiva pelo ato positivo da interpretação; pelo que, se a Savigny pareceu singular o caber a interpretação somente nos casos acidentais de obscuridade nas leis, a mim parece mais que extraordinário o não poder haver uma só lei, sequer, clara e precisa em relação aos fatos sujeitos ao seu domínio, de modo que não seja preciso interpretála (PAULA BAPTISTA, 1984, p. 5).

Para Maximiliano, "A Hermenêutica Jurídica tem por objetivo o estudo e a sistematização dos processos aplicáveis para determinar o sentido e o alcance das expressões do Direito" (MAXIMILIANO, 1961. p. 13). A hermenêutica descobre e fixa os princípios que regem a interpretação, podendo ser designada como "[...] a teoria científica da arte de interpretar" (MAXIMILIANO, 1961. p. 14). Este seria seu objeto.

A interpretação é de certa forma subordinada à hermenêutica, que lhe aponta o caminho. Vê-se aí seu objetivo. Esta subordinação da interpretação, para Maximiliano, se dá a) a uma ciência geral, que ele considera ser a ciência do Direito, obediente, por sua vez, aos postulados da Sociologia; $b$ ) e a uma ciência especial, que é a hermenêutica. Percebe-se que o autor considera a hermenêutica uma parte especial da ciência jurídica e a interpretação o objeto da hermenêutica (MAXIMILIANO, 1961, p. 13). ${ }^{8}$

A interpretação tem por objeto a lei em sentido amplo. Seu objetivo seria "explicar, esclarecer; dar o significado do vocábulo, atitude ou gesto; reproduzir por outras palavras um pensamento exteriorizado; mostrar o sentido verdadeiro de uma expressão; extrair, de frase, sentença ou norma, tudo o que na mesma se contém" (MAXIMILIANO, 1961, p. 23).

\footnotetext{
${ }^{8}$ Não resta claro no texto o conceito de ciência do Direito. Nota-se, entretanto, que para o autor ela, a ciência do Direito, é a grande área do conhecimento no interior da qual a hermenêutica, interpretação e aplicação são pensadas. Para ele, "A Ciência do Direito não é só elemento relativamente criador, apto a suprir lacunas dos textos; mas também um fator de coordenação e de exegese; auxilia a eliminar contradições aparentes e atingir, através da letra rígida, ao ideal jurídico dos contemporâneos [...] A ciência antecede a jurisprudência; é a primeira a inspirar soluções para os casos duvidosos" (MAXIMILIANO, 1961, p. 244). (Grifo do autor). Sobre o papel criativo da ciência do Direito, de forma precursora, (SAVIGNY, 1878, p. 47-48).
} 


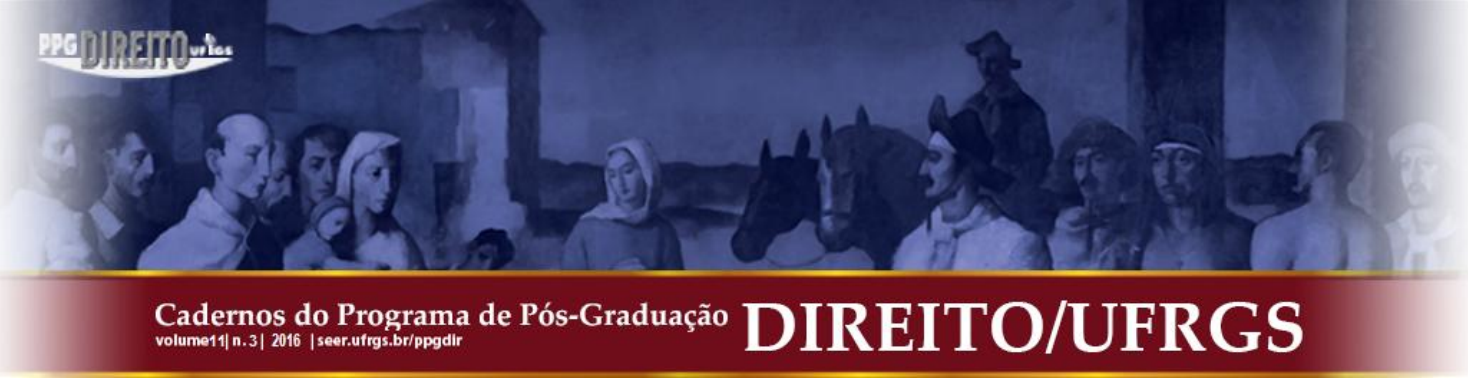

Maximiliano faz uma distinção entre interpretação em sentido amplo, que é realizada pela ciência do Direito e que se ocupa deste como um todo; e a intepretação em sentido restrito, da qual se ocupa a hermenêutica (MAXIMILIANO, 1961, p. 23). Para o autor, como a hermenêutica é um capítulo especial da ciência do Direito, esta não é objeto daquela, mas o contrário. A interpretação, igualmente, possui um caráter prático, que se destina a "[...] revelar o sentido apropriado para a vida real; e conducente a uma decisão reta" (MAXIMILIANO, 1961, p. 24).

Em sentido oposto a Paula Baptista, Maximiliano se opõe à busca da vontade do legislador como critério interpretativo. Para ele, "a lei é mais sábia que o legislador" (MAXIMILIANO, 1961, p. 46). De outra sorte, ainda em oposição a Paula Baptista, a interpretação não tem lugar apenas acidentalmente:

[...] os domínios da Hermenêutica se não estendem só aos textos defeituosos; jamais se limitam ao invólucro verbal [...] Obscuras ou claras, todas as frases jurídicas aparecem aos modernos como suscetíveis de interpretação" (MAXIMILIANO, 1961, p. 54).

Segue o autor questionando e pontuando: “[...]. Que lei é clara? É aquela cujo sentido é expresso pela letra do texto. Para saber se isto acontece, é força procurar saber o sentido, isto é, interpretar" (MAXIMILIANO, 1961, p. 24.). (Grifo do autor). É lícito afirmar que, neste particular, Maximiliano comunga do conceito de interpretação desenvolvido a partir da Escola Histórica de Savigny, no Direito, e da hermenêutica romântica de Schleiermacher, na filosofia, embora não tenha feito referência expressa a este último em seu texto. ${ }^{9}$

\section{O CONCEITO DE INTERPRETAÇÃO NA HERMENÊUTICA GERAL DE SCHLEIERMACHER E NA METODOLOGIA ABSOLUTA DE SAVIGNY}

\subsection{Friedrich Daniel Ernst Schleiermacher}

No âmbito da filosofia, a partir de problemas da filologia e da teologia, Friedrich Schleiermacher pode ser considerado como precursor da "hermenêutica moderna", que, a

\footnotetext{
${ }^{9}$ O fato de Maximiliano não dialogar diretamente com Schleiremacher não exclui a importância de se apresentar o pensamento deste último, na medida em que sua hermenêutica é fruto de um ambiente teórico-filosófico compartilhado por Savigny, este último sim, influência direta de Maximiliano. Sobre as aproximações teóricas e influências recíprocas entre Schleiermacher e Savigny e entre este e outros autores a ele contemporâneos, ver, por todos, (MEDER, 2004, Passim). 


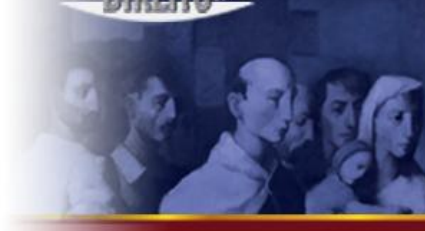

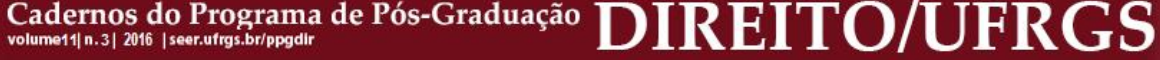

partir dele, adquiriu um caráter geral (SCHLEIERMACHER, 1999. p. 68) ou universal (GADAMER, 2004, p. 254), em contraposição à tradição existente até o início do século XVIII, na qual existiam apenas "hermenêuticas regionais" (RICOEUR, 2008. p. 24), isto é, que lidavam com problemas específicos de suas disciplinas, quais sejam, a hermenêutica filológica, a teológica e a jurídica.

Schleiermacher parte de um pressuposto contrário ao da "hermenêutica iluminista". Ou seja, para ele, o mal-entendido pode ocorrer em qualquer situação, não podendo ser tomado como exceção. Deve sim ser tomado como regra para conceber a forma através da qual a compreensão se dá. A compreensão, por sua vez, é vista como um reconstruir (SCHLEIERMACHER, 2005, p. 115).

Trata-se de uma proposta de "universalização do mal-entendido" que coloca a hermenêutica na base de todo o compreender e que, ademais, entende o compreender e o interpretar como um processo unitário (GADAMER, 2004, p. 407). Isso significa que a interpretação não se faz necessária somente quando a compreensão falha.

A hermenêutica é pensada como "arte da compreensão" (SCHLEIERMACHER, 2005, p. 91). Antes de Schleiermacher, ela era caracterizada por um conjunto de regras para interpretação, com caráter compendial, sem um fundamento filosófico que lhes conferisse justificação. Procurou o autor justamente oferecer esta base (SCHLEIERMACHER, 1999, p. 25). ${ }^{10}$ Isto não significa, entretanto, que as hermenêuticas regionais deixem de existir, mas que podem ser pensadas a partir de fundamentos teóricos comuns. Segundo ele,

\begin{abstract}
A práxis não rigorosa na arte baseia-se na ideia de que a compreensão se dá por si e expressa a meta de modo negativo: os mal-entendidos devem ser evitados. [...]. A práxis mais rigorosa baseia-se na ideia de que a não compreensão se dá por si e que a compreensão precisa ser querida e buscada sob todos os aspectos" (SCHLEIERMACHER, 2005, p. 112-113). (Grifou-se).
\end{abstract}

Metodologicamente o autor trabalha com a relação linguagem-sujeito. Assim, toda a compreensão para ele constitui-se em dois momentos: “[...] compreender o discurso enquanto extraído da linguagem e compreendê-lo enquanto fato naquele que pensa"

\footnotetext{
${ }^{10}$ Segundo Bleicher, "As duas tradições que Schleiermacher retoma no desenvolvimento de sua hermenêutica são a fillosófica transcendental e o romantismo. Daqui fez provir uma forma de questionar as condições de possibilidade da interpretação válida e uma concepção do processo de compreensão. Esta é agora perspectivada como uma reformulação e uma reconstrução criativas" (BLEICHER, 2002. p. 27). No mesmo sentido Ricoeur, acerca do caráter romântico e crítico da hermenêutica de Schleiermacher (RICOEUR, 2008, p. 27). Sobre o conceito de romantismo filosófico, ver (FERRATER MORA, 2001. p. 2050).
}

Cadernos do Programa de Pós-Graduação em Direito PPGDir./UFRGS | Edição Digital | Porto Alegre | Volume XI | Número 3 | 2016 | P. 369 - 384 


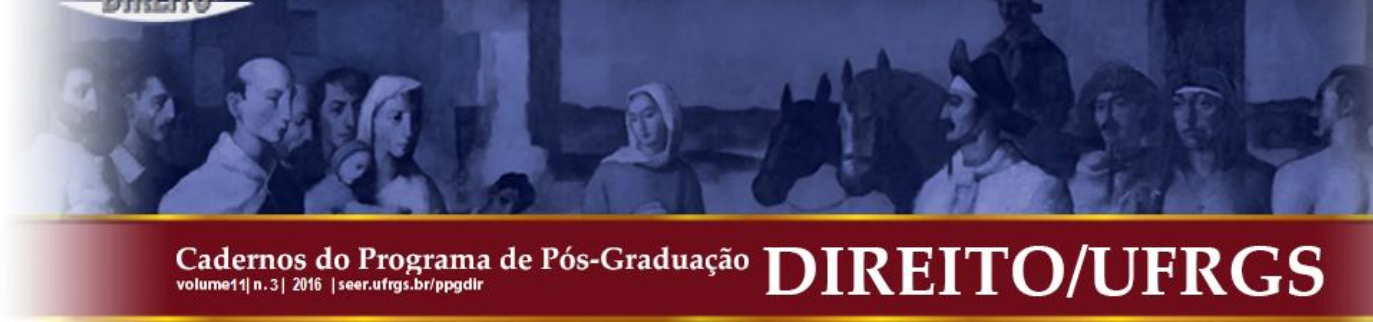

(SCHLEIERMACHER, 2005, p. 95). Quanto ao primeiro aspecto, fala Schleiermacher em “compreensão gramatical”; em “compreensão técnica (ou psicológica)" quanto ao segundo (SCHLEIERMACHER, 1999, Passim). A compreensão é vislumbrada como exposição do pensamento, consiste em uma arte de "[...] compreender o discurso, primeiramente tão bem e, depois, melhor do que o seu autor" (SCHLEIERMACHER, 2005, p. 115).

\subsection{Friedrich Carl von Savigny}

No âmbito do Direito, a partir do início do século XIX, Savigny procurou desenvolver uma proposta de ciência renovada, autônoma, consciente de seus próprios métodos, de caráter objetivo e sistemática. Tal empreendimento começa a ser esboçado em 1802/1803 em suas "lições de Marburgo", onde trabalhou como docente privado, acerca da "Metodologia Jurídica" (SAVIGNY, 1951) (SAVIGNY, 2001). ${ }^{11}$

Savigny, logo na introdução de seu trabalho, concebe o método como sinônimo de sistema. Para construção da ciência do Direito, o autor fala em uma elaboração absoluta e outra voltada aos meios auxiliares. Na elaboração absoluta, pensa em um sistema puro como fundamento. Esta "metodologia absoluta" deveria estabelecer normas para relacionar os meios auxiliares com a elaboração absoluta (SAVIGNY, 2001, p. XV-XVII). Em termos estruturais, é possível perceber uma aproximação da proposta savignyana com o projeto de Schleiermacher, cada um em seu âmbito teórico.

O objeto de estudo para sua "metodologia absoluta" parte de uma concepção histórica do Estado como legislador e refere que o "[...] objetivo da ciência jurídica é, por conseguinte, apresentar historicamente as funções legislativas de um Estado" (SAVIGNY, 2001, p. 1). ${ }^{12}$ Busca ele o que é comum nas disciplinas jurídicas no momento da elaboração legislativa, ou seja, seus princípios comuns. São eles: a ciência legislativa é histórica; filosófica; histórica e filosófica (SAVIGNY, 2001, p. 2).

O aspecto histórico da ciência e do próprio Direito diz respeito ao estudo do material jurídico historicamente elaborado, ou mais precisamente, determinado pela tradição científica

\footnotetext{
${ }^{11}$ Sobre as lições de Marburgo, ver (KANTOROWICZ, 1933, Passim) e (RÜCKERT, 2006. p. 58).

12 Joachim Rückert refere que o "método" de Savigny desenvolveu uma "nova visão de ciência", distanciando-se, assim, fortemente da tradição (RÜCKERT, 2006, p. 59). Na mesma linha, pontua Thiago Reis que "Metodologia jurídica significa, no pensamento de Savigny, a identificação dos elementos segundo os quais seja possível a elaboração científica da jurisprudência, i.e., das condições de uma ciência do direito" (REIS, 2013. p. 29).
} 
dos textos e da ciência (WIEACKER, 1967.p. 421). Entra em jogo neste caráter histórico uma análise propriamente histórica e filológica da matéria jurídica. Para Savigny, “[...] Denominase saber histórico, todo saber de algo objetivamente dado. Por conseguinte, todo o caráter da ciência legislativa deve ser histórico" (SAVIGNY, 2001, p. 2). ${ }^{13}$ A objetividade exigida pela ciência do Direito diz respeito ao método, bem como à própria abordagem do material jurídico, que deve ser visto como objeto.

A tarefa da ciência é elaborar um conteúdo geral que não esteja sujeito ao caso, ou seja, uma elaboração sistemática da ciência do Direito. Esta tarefa se aproxima da filosofia que, "[...] mediante uma completa dedução, deve indicar todo o conteúdo da tarefa geral. Portanto a jurisprudência é uma tarefa filosófica" (SAVIGNY, 2001, p. 5). ${ }^{14}$ Savigny pensa a ideia de sistema, que é tomado como sinônimo de método, no sentido da relação recíproca entre parte e todo. ${ }^{15}$

O autor procura demonstrar como é possível realizar uma elaboração puramente exegética (filológica), ou seja, a separação da lei em seus elementos particulares, e uma elaboração puramente sistemática (filosófica) e acredita que a posterior relação entre ambas é espontânea (SAVIGNY, 2001, p. 7). O sistema exerce a função de ordenar o material jurídico.

Neste sentido entra em questão a mencionada metodologia completa e absoluta (SAVIGNY, 2001, p. 7-8), que deveria servir para possibilitar a coordenação entre a parte filológica, a parte histórica (sendo estas partes da interpretação histórica) e o sistema. Nas lições de Marburgo, Savigny dividiu sua abordagem em três seções: a elaboração filológica da ciência do Direito; a elaboração histórica da ciência do Direito e elaboração sistemática da ciência do Direito. Ao se ocupar da elaboração filológica, o autor se debruça sobre um problema que é central na hermenêutica jurídica, qual seja, a questão da interpretação. A interpretação, ao menos nesta fase inicial de seu pensamento, ocupa um capítulo da metodologia, mais especificamente um capítulo da elaboração filológica do material jurídico.

\footnotetext{
${ }^{13}$ A Escola histórica perseguia um ideal de investigação histórica, mas sem descurar da razão. (WIEACKER, 1967, p. 429).

${ }^{14}$ No texto original consta a expressão "Jurisprudenz" (SAVIGNY, 1951, p. 16). Importa salientar, que no idioma alemão as expressões "Rechtswissenschaft" (literalmente ciência do Direito) e "Jurisprudenz", são tomadas geralmente como sinônimas. Portanto Savigny não está aqui a falar de jurisprudência no sentido de atividade prática e/ou do conjunto de decisões reiteradas dos tribunais. Ver, (CREIFELDS, e WEBER, 2011. p. 983 e 662).

${ }^{15}$ Apesar de Savigny não utilizar a expressão "círculo hermenêutico", é possível fazer um paralelo da sua concepção de sistema com o pensamento de Friedrich Schleiermacher que, no âmbito da sua hermenêutica geral, trabalhou com a relação entre parte e todo como questão central. Sobre o círculo hermenêutico em Schleiermacher, ver (SCHLEIERMACHER, 1999, Passim).
} 


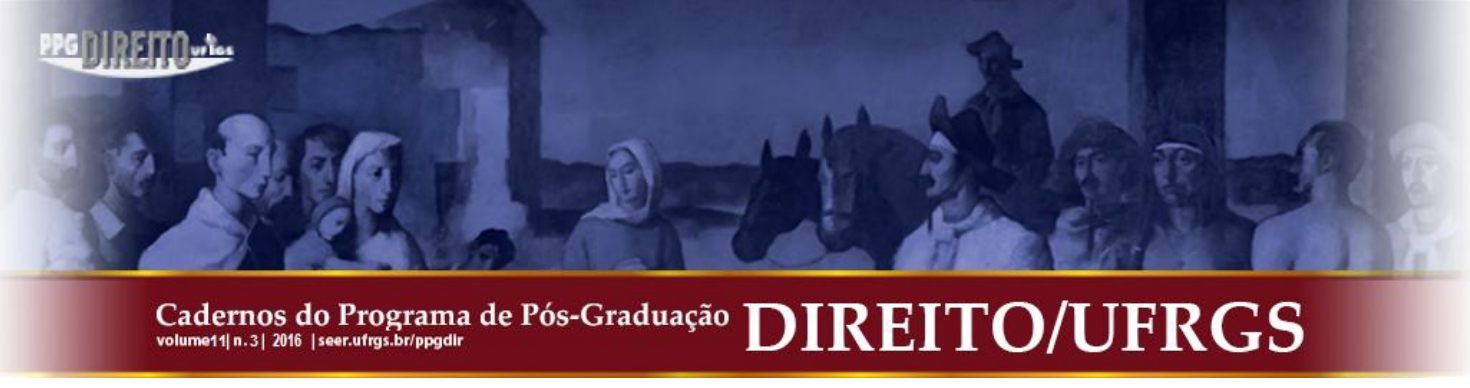

Já na obra "Sistema de Direito Romano" (1840), os quatro elementos da interpretação, a saber, o elemento lógico, o gramatical, o histórico e o sistemático, aparecem novamente pensados em conjunto, diferentemente do que ocorria na obra inicial, em que, como já ressaltado, exegese e sistema eram elaborados separadamente. Igualmente, há uma preocupação em melhor delineá-los conceitualmente, o que também não ocorria na "Metodologia" em 1802 e 1803:

El elemento gramatical de la interpretación tiene por objeto las palabras de que el legislador se sirve para comunicarnos su pensamiento, es decir, el lenguaje de las leyes. El elemento lógico, la descomposición del pensamiento o las relaciones lógicas que unen á sus diferentes partes. El histórico tiene por objeto el estado del derecho existente sobre la materia, en la época en que la ley ha sido dada; determina el modo de acción de la ley y el cambio por ella introducido, que es precisamente lo que el elemento histórico debe esclarecer. Por último, el elemento sistemático tiene por objeto el lazo íntimo que une las instituciones y reglas del derecho en el seno de una vasta unidad. El legislador tenía ante sus ojos tanto este conjunto como los hechos históricos, y, por consiguiente, para apreciar por completo su pensamiento, es necesário que nos expliquemos claramente la acción ejercida por la ley sobre el sistema general del derecho y el lugar que aquella ocupa en este sistema. (SAVIGNY, 1878, p. 150) (Grifou-se).

À semelhança do que propõe Schleiermacher, Savigny advoga que interpretar, "[...] é reconstrução do pensamento (claro ou obscuro, é o mesmo) expresso na lei, enquanto seja possível conhecê-lo na lei. [...]. O conceito usual de interpretação (esclarecimento de uma lei obscura) é completamente inútil" (SAVIGNY, 2001, p. 10). E outros termos, para Savigny, a interpretação não possui um caráter apenas acidental. Trata-se de uma operação sempre necessária para o trato científico do material jurídico.

Apesar de ser referido como um dos principais autores da "hermenêutica jurídica clássica", Savigny não utiliza a expressão "Hermeneutik". Ocupa-se sim da metodologia do Direito ("Methodologie", "Methodik", "Methodenlehre") e emprega o termo latino "Interpretation", que é tomado em regra como sinônimo de "Auslegung" (SAVIGNY, 1951, Passim).

Poder-se-ia dizer com certas reservas que a metodologia está para a interpretação em Savigny como a hermenêutica está para interpretação em Maximiliano. A diferença residiria talvez no papel da metodologia em Savigny, que estaria também na base da ciência jurídica, diferentemente da hermenêutica em Maximiliano, que é um ramo da ciência jurídica. A distinção entre interpretação em sentido amplo e restrito feita por Maximiliano parece apontar nesta direção. O que Maximiliano chama de interpretação feita pela ciência, tendo o 


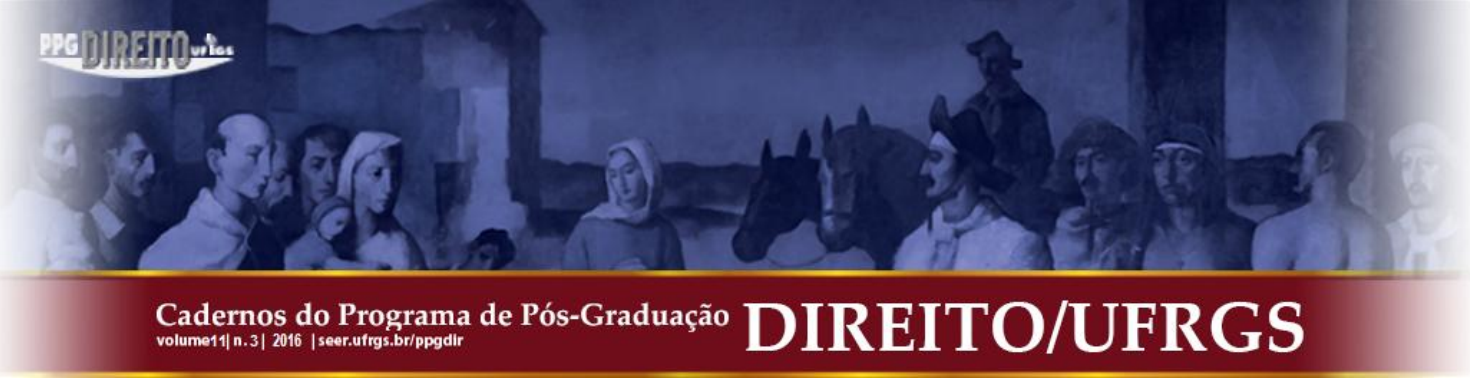

Direito em geral como objeto, não aparece em Savigny como interpretação, que seria a atividade realizada pela metodologia absoluta.

\section{O PAPEL DO INTÉRPRETE E O CONCEITO DE APLICAÇÃO DO DIREITO EM CARLOS MAXIMILIANO}

Maximiliano reconhece o componente pessoal inarredável do intérprete, que impede que este seja reduzido a um autômato. Ademais, pontua que "Talvez constitua a Hermenêutica o capítulo menos seguro, mais impreciso da ciência do Direito; porque partilha da sorte da linguagem" (MAXIMILIANO, 1961, p. 25). É de se frisar o destaque dado por ele tanto para o "problema" da subjetividade quanto para a questão da linguisticidade da interpretação, que são temas caros à hermenêutica filosófica e jurídica e que, por parte dessa, nem sempre receberam ao longo da história o tratamento digno de sua importância. Segundo ele,

Existe entre o legislador e o juiz a mesma relação que entre o dramaturgo e o ator.
Deve este atender às palavras da peça e inspirar-se no seu conteúdo; porém, se é
verdadeiro artista, não se limita a uma reprodução pálida e servil: dá vida ao papel,
encarna de modo particular a personagem, imprime um traço pessoal a
representação, empresta às cenas um certo colorido, variações de matiz quase
imperceptíveis; e de tudo faz ressaltarem aos olhos dos espectadores maravilhados
belezas inesperadas, imprevistas. Assim o magistrado: não procede como insensível
e frio aplicador mecânico de dispositivos; porém como órgão de aperfeiçoamento
destes, intermediário entre a letra morta dos Códigos e a vida real, apto a plasmar,
com a matéria-prima da lei, uma obra de elegância moral e útil à sociedade. Não o
consideram autômato; e, sim, árbitro da adaptação dos textos às espécies ocorrentes,
mediador esclarecido entre o direito individual e o social (MAXIMILIANO, 1961,
p. 83).

Já a aplicação também não se confunde com a interpretação e com a hermenêutica, pois “[...] consiste em enquadrar um caso concreto em uma norma jurídica adequada. Submete às prescrições da lei uma relação da vida real; procura e indica o dispositivo adaptável a um fato determinado" (MAXIMILIANO, 1961, p. 19).

Maximiliano possui uma concepção de aplicação que pressupõe uma determinação prévia da norma jurídica pela interpretação, que não prescinde da hermenêutica, para analisar o caso concreto e suas circunstâncias para, por derradeiro, adaptar o preceito à hipótese (MAXIMILIANO, 1961, p. 21). Outrossim, a hermenêutica não se ocupa dos fatos, que são objeto exclusivo da aplicação (MAXIMILIANO, 1961, p. 22). 


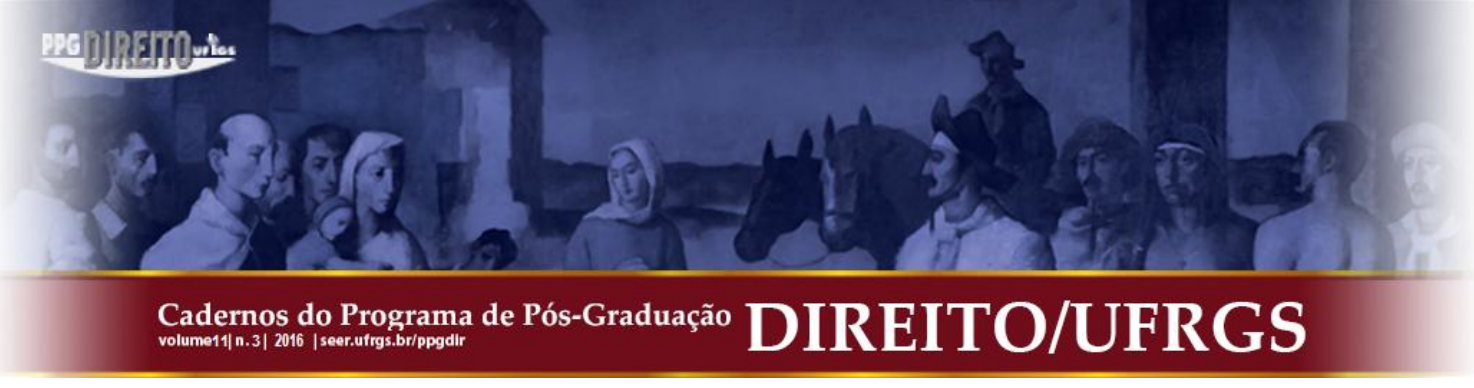

Também no caso da aplicação a subjetividade do aplicador interfere e importa. Segundo o autor, “[...] Não há sistema capaz de prescindir do coeficiente pessoal. A justiça depende, sobretudo, daqueles que a distribuem. O texto é a essência, a matéria-prima, que deve ser plasmada e vivificada pela inteligência [...]”' (MAXIMILIANO, 1961, p. 132). Há certo depósito de confiança nos atributos pessoais do julgador.

Esta concepção pode ser vista como fruto do contato do autor com as teorias críticas da interpretação do final do século XIX início do XX como o chamado Movimento para Direito livre. Alerta o autor, no entanto, que o intérprete - no que poderia ser incluído o aplicador - deve sempre desconfiar de si mesmo no intuito de evitar interpretações viciosas ou incorretas (MAXIMILIANO, 1961, p. 137).

\section{CONSIDERAÇÕES FINAIS}

Nas palavras de Hermann Kantorowicz (1877-1940), “é possível medir o significado histórico de uma obra a partir de três critérios, infelizmente em grande medida entre si independentes: mérito, qualidade e sucesso" (KANTOROWICZ, 1933, p. 457, tradução livre). A obra de Maximiliano não deixa a desejar em nenhum deles.

Quanto ao mérito, se vista como fruto de seu tempo, apresenta-se como um instrumental indispensável para compreender o processo de desenvolvimento teórico no Brasil, por dialogar criticamente de forma séria com a tradição brasileira. Por outro lado, proporciona um amplo conhecimento acerca do debate em nível internacional, ao abordar algumas das principais teorias em voga tanto no século XIX quanto no início do século XX que se ocuparam com o problema da hermenêutica jurídica. Tudo isto em um momento histórico em que o acesso ao conhecimento, em especial em língua estrangeira, não era nada fácil.

No que diz respeito à qualidade, embora não se possa dizer que Maximiliano tenha construído um modelo hermenêutico original, próprio, tal fato não apaga seu brilho, na medida em que o autor, além de ter dialogado profundamente com várias tradições, não se furtou à análise crítica e tomou posições claras acerca dos temas mais candentes que envolveram os debates históricos e que, ainda nos dias atuais, permanecem objeto de importantes disputas no âmbito da teoria e da filosofia do Direito. 


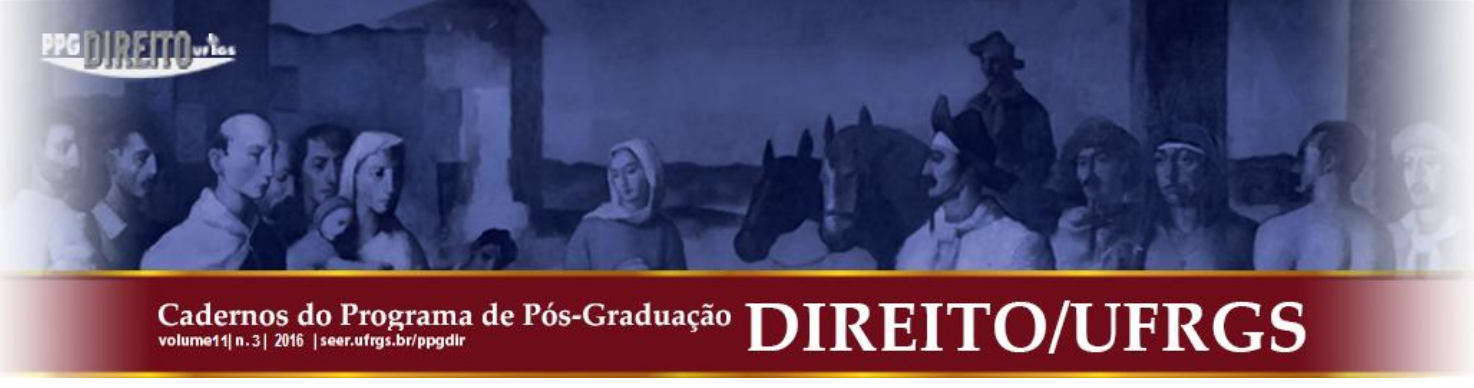

Talvez isso explique o sucesso e a influência que seu pensamento exerce até hoje no país, sendo notório o fato de que sua obra permanece meritoriamente sendo citada tanto na teoria quanto na prática. De se referir que o livro "Hermenêutica e Aplicação do Direito" permanece sendo reeditado, mesmo após cinco décadas do falecimento do autor. Pensa-se, assim, que os influxos de novas teorias, como a recepção no ambiente jurídico da hermenêutica filosófica ou do que se convencionou chamar de "giro linguístico" da filosofia não tornam supérfluo o seu estudo.

Pelo contrário. A obra de Carlos Maximiliano deve permanecer um referencial teórico se se quiser levar a sério aquilo que Gadamer refere em sua hermenêutica filosófica, ou seja, que a compreensão, no que para ele está incluída a questão da interpretação, é um fenômeno que acontece sempre no interior de uma tradição e é por ela marcada (GADAMER, 1998, p. 13), o que implica a necessidade do diálogo e uma atitude de abertura (GADAMER, 2004, p. 358) do intérprete para o diálogo. Ademais, para se evitar julgamentos apressados e caricaturas, que muitas vezes ofuscam o que há de essencial e inevitavelmente malogram o processo compreensivo.

O livro de Maximiliano, neste sentido, é um belo exemplar daquilo que a tradição pode nos oferecer de positivo, sendo digno de ser qualificado como um clássico do pensamento brasileiro.

\section{REFERÊNCIAS}

BLEICHER, J. 2002. Hermenêutica Contemporânea. Tradução de Maria Georgina Segurado. Lisboa: Edições 70, 383 p.

COSTA, M. L. 1984. Apresentação ao livro de Joaquim Ignácio Ramalho. (In) Hermenêutica Jurídica. Edição cuidada por Alcides Tomasetti Jr. São Paulo: Saraiva, p. 85-88.

CREIFELDS, C. WEBER; K. (Herausgegeber). 2011. Rechtswissenchaft. (In) Rechtswörterbuch. 20. Auflage. München: C.H. Beck, 1573 p.

FERRATER MORA, J. 2001. Dicionário de Filosofia. Tomo III. 2. ed. Tradução de Maria Stela Gonçalves et. al. São Paulo: Edições Loyola, 1621 p. 


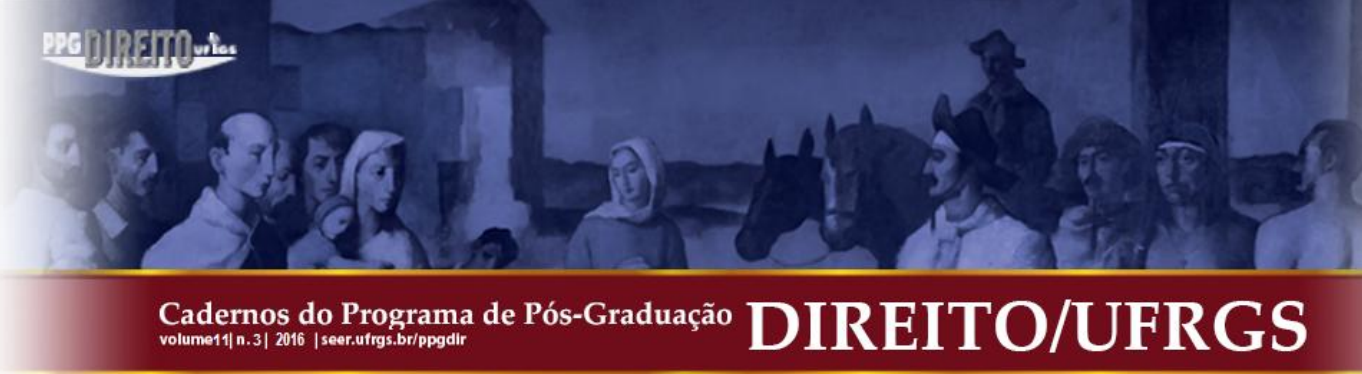

GADAMER, H. G. 1998. O problema da consciência histórica. Pierrre Fruchon (Org.). Rio de Janeiro: Fundação Getúlio Vargas, 72 p.

2004. Verdade e Método I: traços fundamentais de uma hermenêutica filosófica. 6. ed. Tradução de Flávio Paulo Meuer. Petrópolis: Vozes, 631 p.

KANTOROWICZ, H. 1933. Savignys Marburger Methodenlehre. (In) Zeitschrift der Savigny-Stiftung für Rechtsgeschichte. Romanistische Abteilung. Bd 53, Weimar: Hermann Böhlaus Verlag, p. 465-471.

KUHN, T. S. 1970 The Sctructure of Scientific Revolutions. 2. ed. Enlarged. Chicago: University of Chicago Press, 212 p.

MAXIMILIANO, C. 1961. Hermenêutica e Aplicação do Direito. 7. ed. Rio de Janeiro: Freitas Bastos, 503 p.

MEDER, S. 2004. Mißverstehen und Verstehen. Savignys Grundlegung der juristichen Hermeneutik. Tübingen: Mohr Siebeck, 269 p.

PAULA BAPTISTA, F. 1984. Compêndio de hermenêutica jurídica. (In) Hermenêutica Jurídica. Edição cuidada por Alcides Tomasetti Jr. São Paulo: Saraiva, p. 1-80.

REIS, T. 2013. Direito e método na teoria possessória de Savigny. Porto alegre: Sérgio Fabris, 139 p.

RICOEUR, P. 2008. Hermenêutica e Ideologias. Tradução de Hilton Japiassu. Petrópolis: Vozes, $184 \mathrm{p}$.

RIEBSCHLÄGER, K. 1968. Die Freirechtsbewegung. Zur Entwicklung einer soziologischen Rechtsschule. Berlin: Duncker \&. Humblot, 125 p.

RÜCKERT, J. 2006. Friedrich Carl von Savigny, the Legal Method, and the Modernity of Law. (In) Juridica International Law Review. University of Tartu (1632). XI, p. 55-67.

SAVIGNY, F. K. von. 1951. Juristische Methodenlehre. Stuttgart: K. F. Koehler, 73 p. 
2001. Metodologia jurídica. Tradução do alemão para o espanhol de J. J. SantaPinter, Tradução para o português Hebe A. M. Caletti Marenco. Campinas, SP: Edicamp, 89 p.

1878. Sistema del Derecho Romano actual. Tomo I. Traducido del alemán por M. CH. Guenoux. Madrid: F. Górgora y Compañia Editores, 454 p.

SCHLEIERMACHER, F. E. D. 1999. Hermenêutica. Arte e técnica da interpretação. Tradução de Celso Reni Braida. Petrópolis: Vozes, 102 p.

2005. Hermenêutica e Crítica. Volume I. Editado e introduzindo por Manfred Frank a partir da edição original de Friedrich Lücke. Tradução de Aloísio Ruedell. Ijuí: Editora Unijuí, 280 p.

WIEACKER, F. 1967. História do Direito Privado Moderno. 4. ed. Tradução de A. M. Botelho Hespanha. Lisboa: Fundação Calouste Gulbekian, 765 p. 


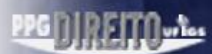

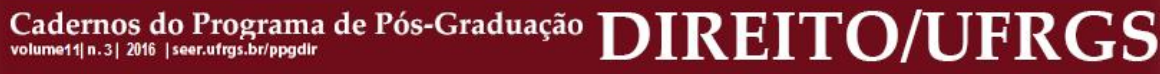

384 